\title{
Localisation of immunoglobulin on the liver cell surface in primary biliary cirrhosis
}

\author{
K KROGSGAARD, U TAGE-JENSEN, P WANTZIN, J ALDERSHVile, \\ F HARDT
}

From the Division of Hepatology, Hvidovre Hospital and the Department of Infectious Diseases $M$ and Medical Department A, Rigshospitalet, Copenhagen, Denmark

SUMMARY Direct immunofluorescence studies were performed on isolated liver cells in order to detect surface localisation of IgG in acute and chronic hepatitis and primary biliary cirrhosis. Membrane-bound IgG was demonstrated in nine patients. Six of eight patients with primary biliary cirrhosis showed granular fluorescence on their liver cell surfaces suggesting that an antibody or immune complex-mediated cytotoxicity might be involved in the pathogenesis of this disease.

Primary biliary cirrhosis (PBC) is a disease of unknown aetiology which largely affects middle-aged women. Many features of PBC such as hypergammaglobulinaemia, presence of autoantibodies, circulating immune complexes, granuloma formation and association with other autoimmune diseases suggest that immune mechanisms may have an important pathogenic role. Recent in vitro studies have indicated that lymphocytes in PBC are cytotoxic to hepatocytes. ${ }^{12}$ Furthermore, large and small circulating immune complexes have been demonstrated, in some series correlating with the disease activity of PBC. ${ }^{34}$ McFarlane et al. ${ }^{5}$ have now found, that many patients with $\mathrm{PBC}$ exhibit in vitro leucocyte migration inhibition in response to a protein fraction of normal human gall-bladder bile, and the same group of workers have also been able to detect biliary tract antigens in circulating immune complexes. ${ }^{6}$

A prerequisite for immune mechanisms as the basis for the primary lesion of the liver involving cellular infiltrate and granuloma formation would be the demonstration of immune reactions taking place in the liver tissue. The present study deals with in vivo fixation of IgG to hepatocytes as a possible indicator of such reactions and compares the findings to other inflammatory liver diseases where such a binding has been shown to take place. ${ }^{7-9}$

\section{Patients and methods}

Twenty-six patients with inflammatory liver disease were included. Diagnoses were all based on histological and clinical examination.

Accepted for publication 23 March 1981
Ten patients had acute viral hepatitis at varying stages, five were classified as "hepatitis B" and five were "non-B."

Five patients had chronic aggressive hepatitis (CAH) and three chronic persistent hepatitis (CPH according to established criteria, ${ }^{10}$ one in each category was type B. Patients were classified as virus-B associated if they had circulating $\mathrm{HBsAg}$ of an anti-hepatitis B core (anti-HBc) titre above $10^{-3}$ without anti-HBs, or if acute hepatitis B initiated the present disease. Two patients with $\mathrm{CAH}$ were on treatment with prednisone, and one $\mathrm{CPH}$ patient with Arabinosid-A (500 mg/day).

Eight patients had PBC according to clinical, serological and histological criteria. ${ }^{11}$ Four patients were untreated at the time of investigation. One patient was receiving prednisone, two patients azathioprine and one was receiving a combination of these two drugs. Daily dosage was $10 \mathrm{mg}$ of prednisone or $100 \mathrm{mg}$ of azathioprine or both.

Seven subjects were included as controls. The indications for biopsy in these patients were suspicion of alcoholic liver disease, hepatitis or liver involvement in systemic diseases. None of the patients had histological signs of inflammatory liver disease, and five had only minor histological changes such as steatosis or unspecific reactive changes.

Serum samples were taken from all patients at the time of biopsy and stored at $-20^{\circ}$ until analysis.

LIVER TISSUE

Tissue was obtained by percutaneous biopsy with the Menghini fine needle technique and the material was bisected. One part was processed for routine histological examination and the other transferred 
into Eagles minimal essential medium, $\mathrm{pH} 7 \cdot 4$ at $37^{\circ} \mathrm{C}$ and a suspension of hepatocytes was immediately prepared by a non-enzymatic technique as described in detail elsewhere.? The vitality of the hepatocytes was tested by phase contrast microscopy.

\section{IMMUNOFLUORESCENCE TESTS}

Detection of in vivo bound IgG to the isolated hepatocytes was done by a direct immunofluorescence technique ${ }^{7}$ using FITC-labelled antihuman IgG specific for gamma chains (Dako, Denmark); specificity controls included blocking with unlabelled antisera. In vitro binding by isolated hepatocytes of IgG from a serum positive for liver-cell-membrane antibody (LMA) was tested by the indirect immunofluorescence test, described by Hopf et al. ${ }^{12}$ In order to exclude pinocytosis or passive adsorption of IgG, routine-tests using an LMA-negative normal human serum were performed.

The patients' sera were examined under code for LMA, antinuclear antibody (ANA), smooth muscle antibody (SMA) and antimitochondrial antibody (AMA) of IgG class by the indirect immunofluorescence test and standard procedures. ${ }^{13}$

The slides were read in a Leitz Ortholux 2 microscope using a Leitz fluorescence objective, fluorit FL $40 / 1 \cdot 30$, for oil immersion in combination with $6.3 \times$ oculars.

\section{VIROLOGY}

The sera were tested for $\mathrm{HBsAg}$, anti-HBs and anti$\mathrm{HBc}$ by radioimmunoassay (Ausria-II, Ausab and Corab, Abbott Laboratories, Diagnostic Division, North Chicago, USA).
BIOCHEMICAL DATA

Where data on liver biochemistry are incorporated, these were assayed at the time of biopsy.

\section{Results}

Table 1 shows the incidence of both in vivo bound IgG to the hepatocyte surface and of LMA in serum in the 26 patients with inflammatory liver disease and the seven controls. Six of eight patients with PBC had in vivo bound IgG; the pattern of staining was fine to coarse granular (Fig. 1a) except in one who had a pattern that tended to be linear. Isolated liver cells from all patients and the seven controls bound IgG from the LMA positive reference serum producing a strong linear fluorescence staining pattern (Fig. 1b) clearly distinguishable from the normal control (Fig. 1c). Furthermore, this reference"serum

Table 1 The frequency of membrane-bound IgG on isolated hepatocytes and of simultaneous circulating liver membrane antibody in 26 patients with inflammatory liver disease and 8 controls

\begin{tabular}{llll}
\hline Disease & $\begin{array}{l}\text { Cases } \\
(n)\end{array}$ & $\begin{array}{l}\text { Membrane IgG } \\
(n)\end{array}$ & $\begin{array}{l}\text { LMA* } \\
(n)\end{array}$ \\
\hline $\begin{array}{c}\text { Acute hepatitis type B } \\
\text { type non-B }\end{array}$ & 5 & 1 & - \\
$\begin{array}{c}\text { Chronic aggressive } \\
\text { hepatitis type B } \\
\text { type non-B }\end{array}$ & 1 & - & - \\
$\begin{array}{c}\text { Chronic persistent } \\
\text { hepatitis type B }\end{array}$ & 1 & 1 & 1 \\
type non-B & 2 & - & - \\
$\begin{array}{l}\text { Primary biliary cirrhosis } \\
\text { Controls }\end{array}$ & 8 & 6 & - \\
\hline
\end{tabular}

* Liver-cell-membrane antibody.

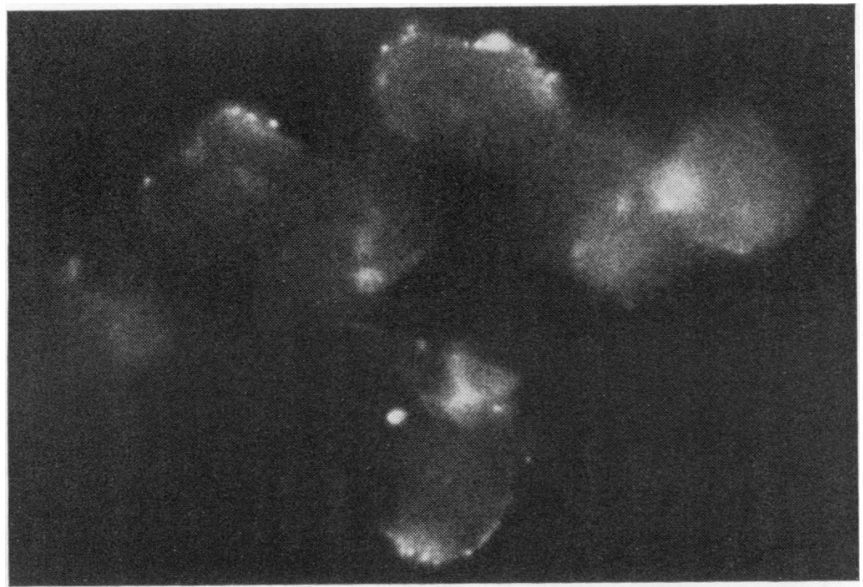

Fig. 1a Photomicrograph of isolated hepatocytes from a patient with primary biliary cirrhosis showing immunofluorescent staining by FITC-antihuman immunoglobulin $\times 100$ 


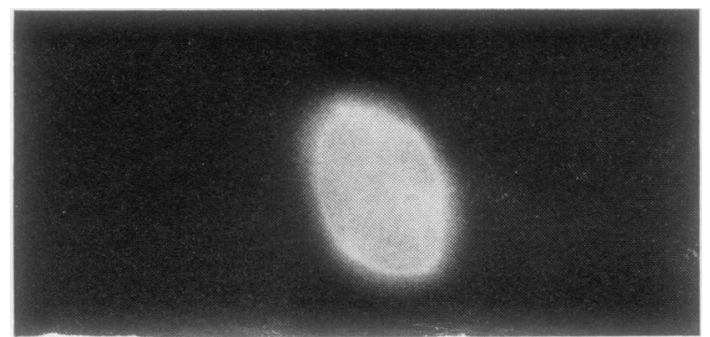

Fig. 1b Photomicrograph of an isolated hepatocyte from a normal control showing immunofluorescent staining by FITC-antihuman immunoglobulin after exposure to an LMA positive serum $\times 100$

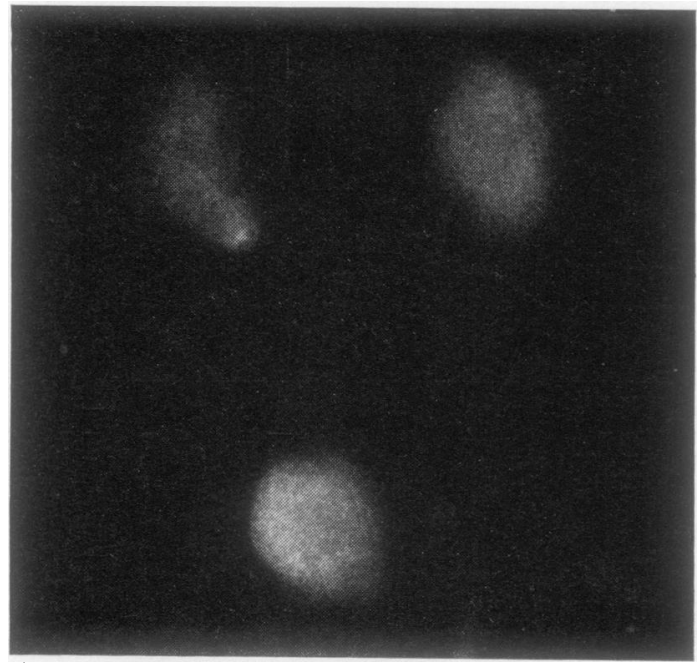

Fig. 1c Photomicrograph of isolated hepatocytes from a normal control without immunofluorescent staining by FITC-antihuman immunoglobulin after exposure to a normal control serum $\times 100$ was found to have an LMA titre at least two doubling dilutions higher when tested with human hepatocytes as compared with rabbit hepatocytes.

In Table 2 the relation between in vivo bound $\mathrm{IgG}$, and some of the serological and biochemical data are shown for the patients with PBC. Of the six patients with in vivo bound IgG, four had markedly raised alkaline phosphatase activities, whereas the two patients with no binding had only moderately raised activities. Seven of the patients had AMA of the IgG class in serum, but the titre was not related to the presence of in vivo bound IgG. The one patient without AMA had LMA, SMA and ANA all of IgG class. This autoantibody profile is usually suggestive of CAH. However, in this patient the clinical and histological features were fully compatible with PBC.

Of five patients with $\mathrm{CAH}$ one without virus $\mathrm{B}$ markers demonstrated in vivo bound IgG on the surface of isolated hepatocytes and at the same time circulating LMA and ANA. Among three patients with CPH one was virus B associated and demonstrated surface bound IgG in the absence of circulating autoantibodies. The above-mentioned two patients both had raised IgG concentrations in contrast to the remaining six patients with chronie hepatitis.

Altogether, two patients had circulating LMA both demonstrated in vivo bound IgG.

\section{Discussion}

In vivo fixation of IgG to the surfaces of hepatocytes was only demonstrated sporadically; however, the findings are consistent with the original report concerning fluorescence patterns and correlation to aetiology and disease activity. ${ }^{12}$ Of special import-

Table 2 Serological data in eight patients with primary biliary cirrhosis investigated for the presence of membrane-bound IgG on isolated hepatocytes

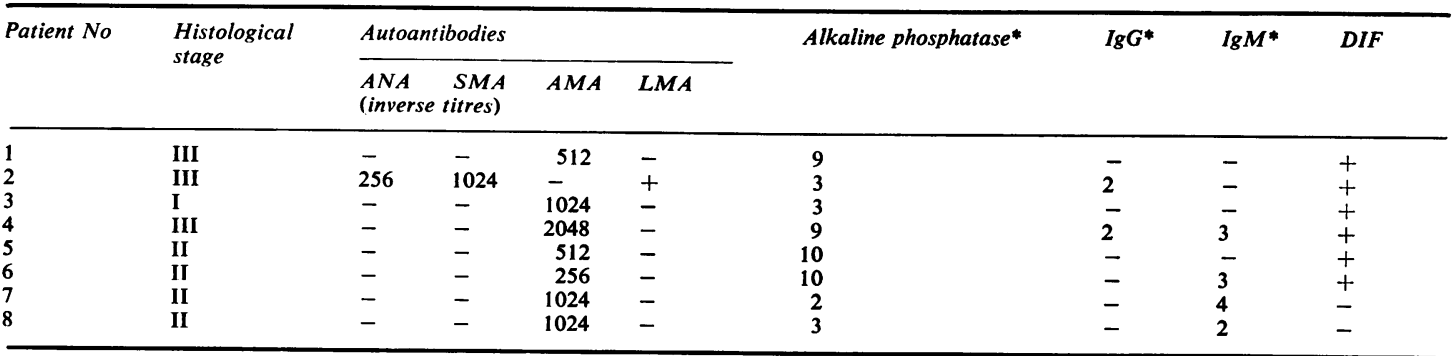

*Expresses increase $\times$ upper normal limit.

DIF = direct immunofluorescence-detection of membrane-bound IgG on hepatocytes.

ANA $=$ antinuclear antibody.

SMA $=$ smooth muscle antibody.

AMA = antimitochondrial antibody

LMA = liver-cell-membrane antibody. 
ance in the description of the autoantibody LMA is the fact that all subjects, including the controls could bind IgG from an LMA-positive (SMA-negative) reference serum. Thus, LMA is directed against normal constitullents of the liver cell membrane and the LM-antigen is obviously expressed on hepatocytes irrespective of liver disease.

The most remarkable finding was the presence of membrane IgG on the hepatocytes from six out of eight patients with PBC, something that to our knowledge has not been demonstrated before. Thomas et al. ${ }^{14}$ and McFarlane et al..$^{5}$ have proposed an autoimmune reaction directed against an antigen associated with the bile canalicular portion of the hepatocyte membrane as the basis for the granulomatous lesions of PBC. The in vivo fixation of IgG to isolated hepatocytes in patients with PBC, demonstrated in the present work, was not related to stage of disease (Table 2), but was also present in the one patient, where no parenchymal involvement was found. Theoretically this IgG could be an antibody directed against bile canalicular antigens, or it could be part of immune complexes, thus forming the basis for an antibody-mediated cytotoxic reaction as proposed above. ${ }^{514}$ This point could not be further clarified due to shortage of material, but the present results do not indicate that AMA is of pathogenic influence.

In conclusion, our results extend the accumulating data suggesting the involvement of altered immune functions in the development of PBC. Biliary tract antigens might be the target of humoral responses, but proof of a causal relation must await identification of the IgG which is fixed to the hepatocyte membrane in vivo and of the putative target antigen involved.

This study was supported by grants from the Ebba Celinder Foundation and the Danish Medical Research Council (grant nos 512-15478, 512-20553) and the Weimann foundation.

\section{References}

${ }^{1}$ Geubel AP, Keller RH, Summerskill WHJ, Dickson ER, Tomasi TB, Shorter RG. Lymphocyte cytotoxicity and inhibition studied with autologous liver cells: observations in chronic active liver disease and primary biliary cirrhosis syndrome. Gastroenterology 1976;71:450-6.

${ }^{2}$ Vierling JM, Nelson DL, Stroker W, Bundy BM, Jones EA. In vitro cell-mediated cytotoxicity in primary biliary cirrhosis and chronic hepatitis: dysfunction and spontaneous cell-mediated cytotoxicity in primary biliary cirrhosis. J Clin Invest 1977;60:1116-28.

${ }^{3}$ Gupta RC, Dickson ER, McDuffie FC, Baggenstoss AH. Circulating IgG complexes in primary biliary cirrhosis: a serial study in forty patients followed for two years. Clin Exp Immunol 1978;34:19-27.

4 Wands IR, Dienstag JL, Bhan AK, Feller ER, Isselbacher KJ. Circulating immune complexes and complement activation in primary biliary cirrhosis. $N$ Engl $J$ Med 1978:298:233-7.

5 McFarlane IG, Wojcicka BM, Tsantoulas DC, Portmann BC, Eddleston ALWF, Williams R. Leucocyte migration inhibition in response to biliary antigens in primary biliary cirrhosis, sclerosing cholangitis and other chronic liver diseases. Gastroenterology 1979;76:1333-40.

- Amoroso P, Vergagni D, Wojcicka BM, et al. Identification of biliary antigens in circulating immune complexes in primary biliary cirrhosis. Clin Exp Immunol $1980 ; 42: 95-8$.

7 Hopf U, Arnold W, Meyer zum Büschenfelde K-H, Förster E, Bolte JP. Studies on the pathogenesis of chronic inflammatory liver disease. I. Membrane-fixed IgG on isolated hepatocytes from patients. Clin Exp Immunol 1975;22:1-8.

${ }^{8}$ Alberti A, Realdi G, Tremolada F, Spina GP. Liver cell surface localisation of hepatitis $B$ antigen and of immunoglobulins in acute and chronic hepatitis and in liver cirrhosis. Clin Exp Immunol 1976;25:396-402.

- Trevisan A, Realdi G, Alberti A, Noventa F. Relationship between membrane-bound immunoglobulin and viral antigens in liver cells from patients with hepatitis B virus infection. Gastroenterology 1979;77:209-14.

${ }^{10}$ De Groote J, Desmet VJ, Gedigk P, et al. A classification of chronic hepatitis. Lancet 1968 ;ii:626-8.

${ }^{11}$ Sherlock S, Scheuer PJ. The presentation and diagnosis of 100 patients with primary biliary cirrhosis. $N$ Engl $J$ Med 1973;289:674-8.

12 Hopf U, Meyer zum Büschenfelde K-H, Arnold W. Detection of a liver membrane autoantibody in HBsAgnegative chronic active hepatitis. $N$ Engl J Med 1976; 294:578-82.

${ }^{13}$ Manthorpe R, Permin H, Tage-Jensen U. Autoantibodies in Sjögrens syndrome. With special reference to livercell-membrane antibody (LMA). Scand $J$ Rheumatol $1979 ; 8: 168-72$.

${ }^{14}$ Thomas HC, Potter BJ, Sherlock S. Is primary biliary cirrhosis an immune complex disease? Lancet 1977;ii: 1261-3.

Requests for reprints to: Dr U Tage-Jensen, Department of Infectious Diseases, Rigshospitalet, Tagensvej 18, DK-2200 Copenhagen N, Denmark. 